\title{
Un Comité de Propietarios para cada AFP
}

Salvador Valdés $\mathrm{P}^{*}$

Ph.D. en Economía, MIT

Profesor Titular de Economía (PUC) y Coordinador del Grupo Mejores Pensiones para Chile convocado en CLAPES UC

Este artículo presenta la propuesta del grupo Mejores Pensiones para Chile, de crear un Comité de Propietarios de Fondos en cada AFP. Su función principal sería encargar a expertos evaluaciones sobre la calidad de los servicios prestados por esa administradora a sus afiliados, incluyendo la gestión financiera, los servicios administrativos y las comisiones cobradas. Los miembros del Comité serían sorteados entre afiliados de la AFP en su mayor parte, debiendo aprobar el examen de asesor previsional de la Superintendencia dentro de cierto plazo. Estas funciones y mecanismo de selección difieren de otras propuestas y creemos hacen gran diferencia.

\section{Antecedentes}

Es antigua la idea de crear un canal eficaz para que los afiliados del sistema contributivo ejerzan su derecho a voz, es decir, a reclamar públicamente. El derecho a voz complementa al derecho de salida, es decir, de irse a otra AFP (ver marco teórico en Hirschmann, 1970).

El derecho a voz estaba ya en el concepto de "tripartismo" de la antigua seguridad social de los años 1920's, tanto en el mundo como en Chile. Sin embargo, las antiguas "Cajas" eran monopólicas, pues la ley impedía al afiliado irse a otra Caja. Además la gestión de las Cajas era cupular, pues sus directorios estaban restringidos a representantes de gremios (laborales y patronales) y de políticos (representantes "del Estado"), generando conocidos conflictos de interés que llevaron a muchas a la insolvencia. Recién a fines de los años 1960's surgen propuestas para dar también al afiliado el derecho a salida, por medio de cambiarse a otra institución previsional. Se entendió que esto era compatible con mantener el derecho a voz. Por ejemplo, la propuesta chilena llamada"El Ladrillo", creaba instituciones previsionales en competencia (los nuevos Fondos de Pensión), y a la vez entregaba su dirección a representantes de los ahorrantes (1973, p. 131-3).

Sin embargo, la selección de representantes por parte de los afiliados en una elección con millones de votantes potenciales no es viable, porque abre riesgos de fracaso por una alta abstención. También es vulnerable a captura por políticos populistas y genera costosas campañas que dan espacio a capturas financieras. ${ }^{1}$

Cuando el servicio incluye la gestión financiera de fondos de pensión enormes y de muy largo plazo, surge una nueva exigencia: la necesidad acuciante de que la gestión sea de primera clase, es decir, que llegue a la frontera eficiente de riesgo-retorno. Es clave evitar el lamentable desempeño de muchos fondos mutuos chilenos, que han sido incapaces de acercarse a dicha frontera, antes de comisiones.

* Email de contacto: svaldesp@uc.cl. Agradezco los comentarios de Fernando López. Cualquier error misión es de mi exclusiva responsabilidad. (2) La propuesta de la Comisión Asesora de la Confederación de la Producción y el Comercio, divulgada en enero de 2017, propone una elección masiva, pero no identifica soluciones a estos conflictos de interés y riesgos. 
Tampoco se pueden repetir las groseras fallas de gestión financiera que exhibieron la mayor parte de las antiguas Cajas chilenas (favoreciendo a operadores del partido controlador, por ejemplo, arrendándoles inmuebles con un canon fijo en pesos, mantenido por décadas a pesar de inflaciones altas; ausencia de inversiones en el exterior; docilidad para comprar bonos del fisco sin protección inflacionaria, etc.). Quizá esta nueva necesidad explique en parte la apuesta del gobierno militar por encargar la gestión de las instituciones administradoras a sociedades anónimas. Como es sabido, esta forma social es la más avanzada en cuanto a eficacia de la gestión para actividades de gran escala, gracias a los numerosos perfeccionamientos a las leyes de sociedades aportados por legisladores de numerosos países desde la década de 1850. Esos perfeccionamientos han limitado muchísimos conflictos de interés.

Sin embargo, desde 2016 distintos observadores estiman que esa apuesta está casi perdida en Chile, pues las AFP estarían perdiendo su "licencia social" para operar: las encuestas revelan que desde 2012 las AFP han atraído la desconfianza de fracciones mayoritarias de sus afiliados.

El desapego parece mutuo. No se sabe de alguna AFP donde el cuadro de mando integral, revisado cada mes por los ejecutivos, incluya una mirada al monto de las pensiones nuevas, antiguas y futuras, con el fin de gestionar soluciones inmediatas ante una caída. También es un hecho que ningún directorio de AFP defendió a sus pensionados con pensión mínima de la discriminación que les aplicó la reforma de 2008, al negarles el acceso al subsidio APS, siendo que otros que tenían pensión mínima en las Cajas sí lo obtuvieron. ${ }^{2}$

\section{Objetivos de la propuesta}

La propuesta de crear un Comité de propietarios en cada AFP tiene 3 objetivos. Primero, fortalecer la identidad de los fondos de pensiones como entes que difieren de las administradoras y cuya propiedad es de los afiliados. Segundo, encausar las críticas y apoyos de los afiliados con su administradora, abriendo un canal para el diálogo constructivo.

Tercero, aprovechar las economías de escala en la elaboración de un bien semipúblico o"bien club", como es la comparación continua calidad/precio de las prestaciones que una administradora da a todos sus afiliados. Para comparar calidad de modo continuo se requieren estudios caros y además sus metodologías están sujetas a innovación, lo cual favorece la centralización en la compra de esos estudios. Ello exige un mandante que actúe por cuenta de los afiliados a una AFP, como el Comité de Propietarios. El grupo Mejores Pensiones para Chile (2016) estimó que esas comparaciones no pueden ser realizadas bien por un servicio estatal - como la Superintendencia de Pensiones - porque su obligación de ser imparcial y la presencia de aspectos cualitativos le impiden pronunciarse con la agudeza necesaria, ni pronunciarse a nivel del subconjunto de afiliados de una sola AFP. Por ejemplo, la Superintendencia nunca advirtió a los afiliados de AFP Planvital antes de 2012, que se les cobraban comisiones mucho mayores que en otras AFP, por servicios de similar calidad.

Al mismo tiempo, el grupo estimó que esos 3 objetivos no deben ser alcanzados por medio del sacrificio de logros en la gestión financiera de los fondos de pensiones. En este servicio, las AFP chilenas han logrado que los retornos brutos de los fondos que gestionan se acerquen a la frontera riesgo-retorno global. En una comparación internacional para los últimos 5 años, han estado en el grupo de gestores de fondos de pensiones con buenos retornos (OCDE, 2015, Tabla 6 en p. 37). ${ }^{3}$ Ello justifica preservar la forma social de sociedad anónima para las AFP.

También se estimó esencial preservar la red de responsabilidades e inhabilidades para los directores de AFP, que Chile ha desarrollado a lo largo de más de 30 reformas legales aplicadas después de la creación del sistema. Esa red depende de una oposición real y constructiva entre la Superintendencia y los directorios de las AFP, que ha sido exitosa en el contexto chileno de serias debilidades institucionales en el Estado.

El movimiento No + AFP estima que el Estado chileno sería capaz de replicar esa red por medio de la creación de una "institución administradora de derecho público de la Seguridad y Previsión Social, autónoma de otras instituciones del Estado y del gobierno de turno, sin fines de lucro, con individualidad jurídica, financiera, contable y administrativa." (Informe, 2016). Sin embargo, esa AFP estaría libre de la competencia de otras administradoras. Tampoco se despediría al directorio cuando su desempeño financiero fuera inferior a la cartera de referencia dada por las AFP rivales, como exige hoy la ley a las administradoras privadas, vía rentabilidad mínima relativa. La autonomía propuesta impide que la Superintendencia de Pensiones fiscalice de

(3) La ley 20.255 aplicó esa discriminación impresentable por medio del Título VIII, artículos 6, 7, 8 y 9.

(4) Las AFP chilenas dan más de 100 servicios administrativos además de la gestión de fondos, pero la ley las obliga a cobrar una sola comisión. Si una AFP quiere ganar más en servicios administrativos sube su comisión, pero eso no afecta en nada su gestión del fondo de pensiones. Por eso, sería un error usar la "TIR del afiliado", un indicador de rentabilidad que resta la comisión única, para comparar con administradoras de otros países cuyo menú de servicios administrativos prestados difiera del chileno. 
verdad a esa hipotética AFP. Tampoco ayuda que el directorio de esa AFP sea designado por partidos políticos chilenos, dada la baja confianza ciudadana en ellos, y el escándalo por la reciente designación de una política sin experiencia litigante al Consejo de Defensa del Estado. ${ }^{4}$

El grupo estimó que para satisfacer todos estos objetivos se requieren dos directorios diferentes: uno dedicado a prestar servicios con máxima eficiencia, y otro dedicado a los 3 objetivos planteados: constituir una cara visible institucional ante la opinión pública que señalice la identidad independiente del Fondo de Pensiones, dar voz a los propietarios de los fondos y aprovechar economías de escala en la evaluación del desempeño de la AFP.

\section{Propuesta: Crear un Comité de Propietarios de Fondos en cada AFP ${ }^{5}$}

¿Cómo conformar estos Comités? Una selección por sorteo es ciudadana. También puede ser complementada con requisitos de conocimiento a cada comisionado. Y las experiencias de Australia y Dinamarca indican que los dirigentes sindicales y la sociedad comprenden mejor un sistema de pensiones cuando participan en su vigilancia.

El grupo propuso que los miembros tengan tres orígenes: (i) miembros elegidos por sorteos sucesivos entre afiliados. Cada sorteado entra a un proceso de verificación de requisitos, por ejemplo más de 3 años de afiliación, suficiente densidad de cotizaciones, declarar interés en el cargo, superar incompatibilidades e inhabilidades, y aprobar el examen para asesores previsionales dentro de un plazo prudente. Se sortearía desde estratos de edad, ingreso imponible y sexo, representativos de los afiliados de cada fondo de pensiones, hasta completar el cupo; (ii) miembros designados por los principales sindicatos y gremios empresariales. La mitad de éstos deberían ser personas con alta calificación técnica, que aprueben el examen para asesores previsionales; $y$ (iii) miembros designados por su calificación técnica, por un comité de búsqueda integrado por delegados de la Comisión de Valores, de la Superintendencia de Pensiones y del Consejo del Banco Central. Todos deben mantenerse afiliados a esa AFP.

Según la propuesta, es esencial que los miembros de los Comités estén sujetos a las normas de incompatibilidad, inhabilidad y probidad para funcionarios públicos, a las normas sobre conflictos de interés que definen las leyes de valores y de sociedades anónimas y a las prohibiciones de la ley 19.496 para las organizaciones de consumidores.
Esto requiere de ley, pues no basta el enfoque voluntario que están ensayando algunas AFP.

Los derechos y facultades del Comité serían las siguientes: (a) encargar evaluaciones expertas sobre la calidad de los servicios prestados por la administradora a los afiliados -incluyendo la gestión de cartera recibida por su fondo de pensiones- y su relación con las comisiones o precios pagados a la administradora, comparado con otras. Sólo podría encargar evaluaciones a expertos inscritos en un registro que la Superintendencia mantendrá con este fin; (b) difundir los resultados, con el fin de orientar y educar a los afiliados en general, para un mejor ejercicio de su derecho a cambiarse de AFP; (c) recibir opiniones de los afiliados de esa AFP, utilizando sólo aquellos canales de contacto que determine el reglamento; (d) asignar por concurso público aquella proporción del Fondo de Educación Previsional (FEP) que corresponda a los afiliados de la AFP respectiva, con los criterios que fije el Comité, no el gobierno de turno. El Comité estaría obligado a evaluar los proyectos educativos con expertos externos inscritos en un registro de la Superintendencia, tanto en términos de validez técnica del contenido como de efectividad educativa.

La propuesta incluye que los miembros de cada Comité de Propietarios duren a lo menos 3 años en sus cargos, con reuniones mensuales, de modo que acumulen conocimiento. Para cobrar dieta, un miembro tendría que participar en un número mínimo de sesiones al año. Habría reglas sobre la vocería. El presupuesto para financiar estudios y su difusión puede ser obtenido en parte del FEP y también en parte del mismo Fondo de Pensiones, con un impacto ínfimo. La Superintendencia de Pensiones fiscalizaría a estos Comités.

\section{Comentarios y aclaraciones}

Esta Propuesta es cuidadosa en evitar explícitamente que los Comités de Propietarios asuman responsabilidades en la administración de la cartera de inversiones, en la selección de subadministradores y en la votación en juntas de accionistas y de acreedores, sea para designar directores, aprobar fusiones, u otras. El Comité propuesto no tiene la representación de los afiliados. Por eso, no puede ser facultado para votar en esas juntas, donde el Fondo de Pensiones es socio. En cambio, se propuso que el Comité pueda encargar evaluaciones de esas (y otras) actuaciones de la administradora y emitir recomendaciones a los afiliados, de modo que cada afiliado decida salir o entrar individualmente.

(5) Es paradójico que el movimiento "No + AFP" proponga crear una AFP mucho más poderosa que la AFP estatal prevista por el proyecto de ley de 2014, a la cual criticó duramente.

(6) Es la propuesta \# 1 del Informe Primero del grupo Mejores Pensiones para Chile (2016). 
La responsabilidad de administrar la cartera de inversiones está entregada hoy por la ley a los directores de las administradoras, por una razón sólida: son actividades profesionales complejas y especializadas. Además, el voto en las juntas mencionadas afecta fuertemente el resultado de la gestión de cartera, que es uno de los principales servicios provistos por cada Administradora a los afiliados. Abandonar este diseño sería inconveniente, porque liberaría a los directores de AFP de gran parte de sus actuales responsabilidades. También liberaría a los propietarios de la administradora de su actual obligación de otorgar la garantía de rentabilidad mínima relativa ${ }^{6} y$ de su obligación de coinversión (encaje) ${ }^{7}$.

La propuesta también evita dar al Comité facultades que puedan colisionar con el derecho de cada afiliado a discrepar del Comité y a actuar de manera independiente de lo que recomiende éste. Del mismo modo, la propuesta no permite al Comité arrogarse la representación o defensa judicial o extrajudicial de ningún afiliado, y menos de todos ellos.

El Comité propuesto parecería tener similitudes con los Comités de Vigilancia que existen en los Fondos de Inversión en todo el mundo (por ejemplo, ley SarbanesOxley de 2002 en EE.UU., y también en la legislación chilena desde la ley 18.815, cuya sucesora es la ley 20.712). Sin embargo, las funciones tradicionales de los Comités de Vigilancia ya han sido entregadas a la Superintendencia en este caso. ${ }^{8} \mathrm{El}$ Comité propuesto también parecería tener similitudes con la Comisión de Usuarios creada por la ley de 2008; sin embargo ella fue enfocada hacia la política pública de pensiones, que es única. En cambio, los Comités se enfocan a generar evaluaciones de la calidad de los servicios recibidos desde cada administradora, por separado porque son diferentes.

Algunas actividades que parecen similares a esta propuesta no lo son realmente, como ocurre con la "cuenta pública" de AFP Habitat. En marzo de 2017, AFP Cuprum anunció que establecerá un "Comité de Afiliados" seleccionado por sorteo. El grupo Mejores Pensiones para Chile lo valoró como un primer paso en busca de mejorar el funcionamiento de nuestro sistema previsional. Sin embargo, también manifestó las siguientes aprensiones sobre ese diseño (ver Declaración Pública, 2017): no contempla presupuesto para contratar informes independientes sobre el desempeño de la AFP, por lo que el Comité se limitaría a oír lo que diga la AFP sobre sí misma. Tampoco tiene una institucionalidad de probidad que evite malas prácticas. Asimismo, en vez de darles una continuidad útil (por ejemplo, 3 años, con sesiones mensuales), cada miembro del Comité sólo participaría en 4 reuniones (una por trimestre) antes de ser sustituido.

\section{Referencias}

Grupo Mejores Pensiones para Chile (2016) Informe Primero: El descontento con las pensiones: 7 conclusiones y 12 propuestas, Documento de Trabajo $\mathrm{N}^{\circ} 27$, Noviembre 23, ClapesUC, Santiago, http://www.clapesuc.cl/ noticias/?filter=grupo-mejores-pensiones

Grupo Mejores Pensiones para Chile (2017) Declaración Pública 06 de marzo, en http://www.clapesuc.cl/ noticias/?filter=grupo-mejores-pensiones

Informe de la Comisión Asesora de la Confederación de la Producción y el Comercio (2017) http://www.cpc.cl/ para-lograr-una-mejora-efectiva-y-sustancial-de-laspensiones-de-todos-los-chilenos-la-comision-asesorade-pensiones-de-la-cpc-presento-un-paquete-integralde-22-propuestas-en-un-informe-que-contie/

Informe de Coordinadora Nacional No Más AFP (2016) Nueva Propuesta Previsional Para Chile, 28 de Noviembre de 2016, http://www.nomasafp.cl/inicio/?page_id=11

Hirschmann, A.O. (1970) Exit, voice, and loyalty: Responses to decline in firms, organizations, and states, Harvard University Press, ISBN 9780674276604

OCDE (2015) Annual Survey of Large Pension Funds and Public Pension Reserve Funds 2015, http://www.oecd.org/finance/ private-pensions/36316399.pdf

Sanfuentes, E. y otros (1973) El Ladrillo: Bases de la Política Económica del Gobierno Militar Chileno, Edición 1992 del Centro de Estudios Públicos, Santiago.

(7) La ley actual aplica multas importantes a aquella administradora que no logra que el fondo de pensiones al que presta servicio obtenga una rentabilidad

(8) No podría obligarse a las administradoras a co-invertir sumas importantes, como las exigidas por la ley actual, en un fondo administrado por el Comité. Tampoco sería posible exigir a los miembros de un Comité formado como se propone aquí, responder patrimonialmente por falencias, como hace la actual ley con el directorio. suficiente en comparación las rentabilidades que obtiene el promedio de los demás fondos de pensiones (benchmark relativo).

(9) Las funciones del Comité de Vigilancia de un Fondo de Inversión ya están incluídas en las obligaciones de fiscalización de la Superintendencia de Pensiones, que ésta ejerce bien: (a) comprobar que las inversiones se hagan conforme a la regulación; (b) comprobar que la administradora entregue información oportuna; y (c) comprobar que la administradora cumpla con el "reglamento" del Fondo (en el caso de los fondos de pensiones, ese reglamento sería la ley). 